\title{
USING THE TL SINGLE-ALIQUOT REGENERATIVE-DOSE PROTOCOL FOR THE VERIFICATION OF THE CHRONOLOGY OF THE TEUTONIC ORDER CASTLE IN MALBORK
}

\author{
ALICJA CHRUŚCIŃSKA ${ }^{1}$, BERNARD JESIONOWSKI ${ }^{2}$, HUBERT L. OCZKOWSKI ${ }^{1}$ \\ and KRZYSZTOF R. PRZEGIĘTKA ${ }^{1}$ \\ ${ }^{I}$ Institute of Physics, Nicolaus Copernicus University, \\ Grudziadzka 5, 87-100 Toruń, Poland \\ ${ }^{2}$ Malbork Castle Museum, \\ Starościńska 1, 82-200 Malbork, Poland
}

Received 2 June 2007

Accepted 12 November 2007

\begin{abstract}
The Teutonic Order Castle in Malbork is one of the precious medieval monuments in Europe. Because of the lack of natural rock resources in Pomerania, its walls are built almost exclusively of bricks. The huge volume and rich historical knowledge about the Malbork Castle makes it a marvellous object for TL dating. The parts of well known age can serve for the verification and improvement of dating method. Subsequently, gained in such way knowledge and experience can be applied for discovering the history of the rest of the castle. Here, the preliminary results of investigations which are still in progress, are presented for 5 brick samples. The applied TL dating procedure is described in detail. The very good accuracy of equivalent dose is achieved by the TL single-aliquot regenerative-dose protocol. The effect of wall inhomogeneity connected with the difference between the activity of the brick and mortar is discussed.
\end{abstract}

Keywords: luminescence dating, bricks, Malbork Castle.

\section{INTRODUCTION}

After the first application of TL dating to pottery samples in 1960s, some attempts to date architectural objects were undertaken (Goedicke et al., 1981 and 1986; Abrahamsen et al., 1996; Banerjee et al., 1999; Bailiff and Holland, 2000; Göksu and Schwenk, 2000; Antrobus, 2004; Sanderson and Bingham, 2004). The accuracy of TL dating achievable earlier could not satisfy historians of art, but recently the development of luminescence measurement technique and the intensive research in field of retrospective dosimetry (Better-Jensen and Murray, 1999; Bailiff and Mikhailik, 2004) using luminescence of building materials have led to significant improvement of dating precision. This has encouraged us to renew cooperation with historians of art.

The Teutonic Order Castle in Malbork (Powierski, 1979; Torbus, 1998) is an object which belongs to the

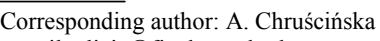
e-mail: alicja@fizyka.umk.pl

ISSN 1897-1695 (online), 1733-8387 (print) @ 2008 GADAM Centre, Institute of Physics, Silesian University of Technology.

All rights reserved. most significant medieval monuments in Poland due to its historical standing and capacity,. The knowledge about its chronology is based on a small number of diffused medieval documents and results of investigations which have been conducted by historians and historians of art for more than 200 years. However, recently some new observations appeared, which seem to undermine statements which were commonly accepted before (Trupinda, 2006; Jesionowski, 2006). Some researchers presented novel concepts concerning the history of the Malbork Castle. In this context, the application of an absolute research method, such as the TL dating, allowing verification of newly postulated ideas on the history of the fortress, is required.

The known historical facts about the chronology of some parts of the Castle give an opportunity to test the TL method in this field of application. The correct results obtained for the sample of known age can be treated as a confirmation of the validity of the age determined for architectural objects whose date of building is unknown or questionable. There are a few sites in the Malbork Castle that are well defined from the historical point of 
view. Nobody doubts the chronology of the north wing of so called High Castle. Historical sources report the forming of the Malbork convent in 1280, so the building which fulfilled the monastic rules had to exist before that year. It is also clear that this part of monastery was subjected to sizeable transformation in the years 1331-1343. The successful dating of bricks from these sites justifies the application of the TL dating method for the rest of the fortress. A part of the Middle Castle - the west wing with Grand Masters' Palace construction is commonly thought to originate from the years 1290-1309. The next site of sampling was chosen because of the need of a settlement between the two possible dates of building. A part of the Middle Castle including the Great Refectory - the largest room in the castle, is dated to be from 1315-1325, but some architectural analysis indicate that it could have been completed before the year 1285 .

The dating procedure applied for brick samples is described in detail. Factors which influence the calculated age, such as moisture content or mortar activity, are analysed. Attempts undertaken in order to estimate the possible errors connected with these factors are also presented.

\section{ARCHEOLOGICAL SITE - OUTLINE OF THE HISTORY}

In the early 13th century the Teutonic Order initiated its crusades to the territories of the Lower Vistula Pomerania - a region inhabited since prehistoric times by the Prussians, a tribe of Baltic origin who were pagans. The knights started to build a castle, called then St. Mary's Stronghold, on the peninsula on the right bank of the Nogat River before the 1280 s. A quadrangular convent building with a chapel, chapter house, dormitory, refectory and an enclosed courtyard with a bailey had been raised. In 1309, the Teutonic Order's headquarters was moved to Malbork. In this way, the castle became the capital of the powerful state. The fortress turned out to be insufficiently equipped for its new role. A redevelopment was carried out during the next 40 years and it changed the convent into the heavily defended High Castle, which was surrounded by deep moats and several circuits of curtain walls and included such remarkable structures as the Church of Our Lady, enlarged in these times by the addition of a new presbytery, and the burial place of the grand masters - St. Anne's Chapel. The former bailey was transformed into a large and serviceable residential quarters, where visiting knights from Western Europe could stay - the Middle Castle. As well as residential rooms, it included the Great Refectory (the largest room in the castle) with beautiful fan vaulting, the Infirmary, where the sick and elderly members of the Order were cared for, and the Grand Masters' Palace. A third element - the Low Castle, now usually referred to as the Outer Bailey, was added to the defense during the 14th and early 15 th centuries. Canons and military vehicles were stored in a large armory - the Karwan. Additional moats and curtain walls with numerous towers surrounded the Outer Bailey with its riverside granary and other service buildings, such as a bell foundry, stables and a brewery. The Malbork Castle is a unique creation, with no equiva- lent in European Gothic architecture. It fell into decay after the first partition of Poland between Austria, Prussia, and Russia in 1772 , but was scrupulously rebuilt in the 19th and early 20th centuries as well as after the partial damage at the end of World War II.

\section{EXPERIMENTAL}

After detailed analysis of the Castle history and geographical location three sites were carefully chosen in the Castle cellars for brick collection in such a way that one can assume that the moisture conditions and the level of cosmic radiation (see also sec. 4) had been stable during the whole period of natural dose accumulation. The Castle had been located on the low riverside and the ground water table is thought to have been stable through the ages. So the area is rather constantly wet. It should be stressed here that the cellars are original and wellpreserved, they were not rebuilt or uncovered for any period in the past, so the moisture conditions in the cellars were constant. Likely seasonal moisture changes which are just investigated can be the most important, but not very considerable in relation to the absolute moisture. Two individual cores of bricks separated in the wall by more than $1 \mathrm{~m}$, were taken from the north wing of the High Castle (samples Mal1 and Mal2) and also from the Grand Masters' Palace in the west wing of the Middle Castle (samples Mal3 and Mal4). One core was collected from the cellar under the Great Refectory in the Middle Castle (sample Mal5). The places of sample collection are presented in Fig. 1.

The quartz inclusions technique was applied. Brick cores ( $6 \mathrm{~cm}$ in diameter) were taken from the walls by means of a crown drill. The outer part, which could be affected by light, was removed. Subsequently, the samples were crushed and sieved to obtain grains of the size between 200 and $100 \mu \mathrm{m}$. This fraction was etched with $\mathrm{HF}(40 \%, 30 \mathrm{~min})$ and again sieved in order to eliminate the fine fraction before the heavy liquid separation in a solution of sodium polytungstate. Two densities of heavy liquid were used for separation: $2.70 \mathrm{~g} / \mathrm{cm}^{3}$ and $2.62 \mathrm{~g} / \mathrm{cm}^{3}$. The final step of the procedure was a repeated etching in $\mathrm{HF}(40 \%, 15 \mathrm{~min})$.

A procedure following TL single-aliquot regenerative-dose protocol (Bailiff and Petrov, 1999; Murray and Roberts, 1998) was applied for the archaeological (equivalent) dose determination. Risø TL/OSL System TL-DA-12 equipped with conventional CN7-59 filter (Aitken, 1985) was used for the TL measurements. The $\mathrm{TL}$ curves were registered during heating to $500^{\circ} \mathrm{C}$ with the rate of $5^{\circ} \mathrm{C} / \mathrm{s}$. 24 aliquots of $10 \mathrm{mg}$ were used for each sample. Experimental sequence included several cycles. Each of them was as follows:

- $\quad$ i-th $\beta$ regenerative dose, preheat to $140^{\circ} \mathrm{C}$;

- glow curve registration during heating to $500^{\circ} \mathrm{C}$;

- test dose, preheat to $140^{\circ} \mathrm{C}$;

- glow curve registration during heating to $500^{\circ} \mathrm{C}$;

All heating and preheat runs were realised with the rate of $5^{\circ} \mathrm{C} / \mathrm{s}$. The TL measurement after the test dose, which was kept constant as $10 \mathrm{~s}$ (seconds of irradiation with $\beta$ source, $1 \mathrm{~s}$ of irradiation gives a dose of 46.1(6) mGy), was used for the correction of the sensitiv- 


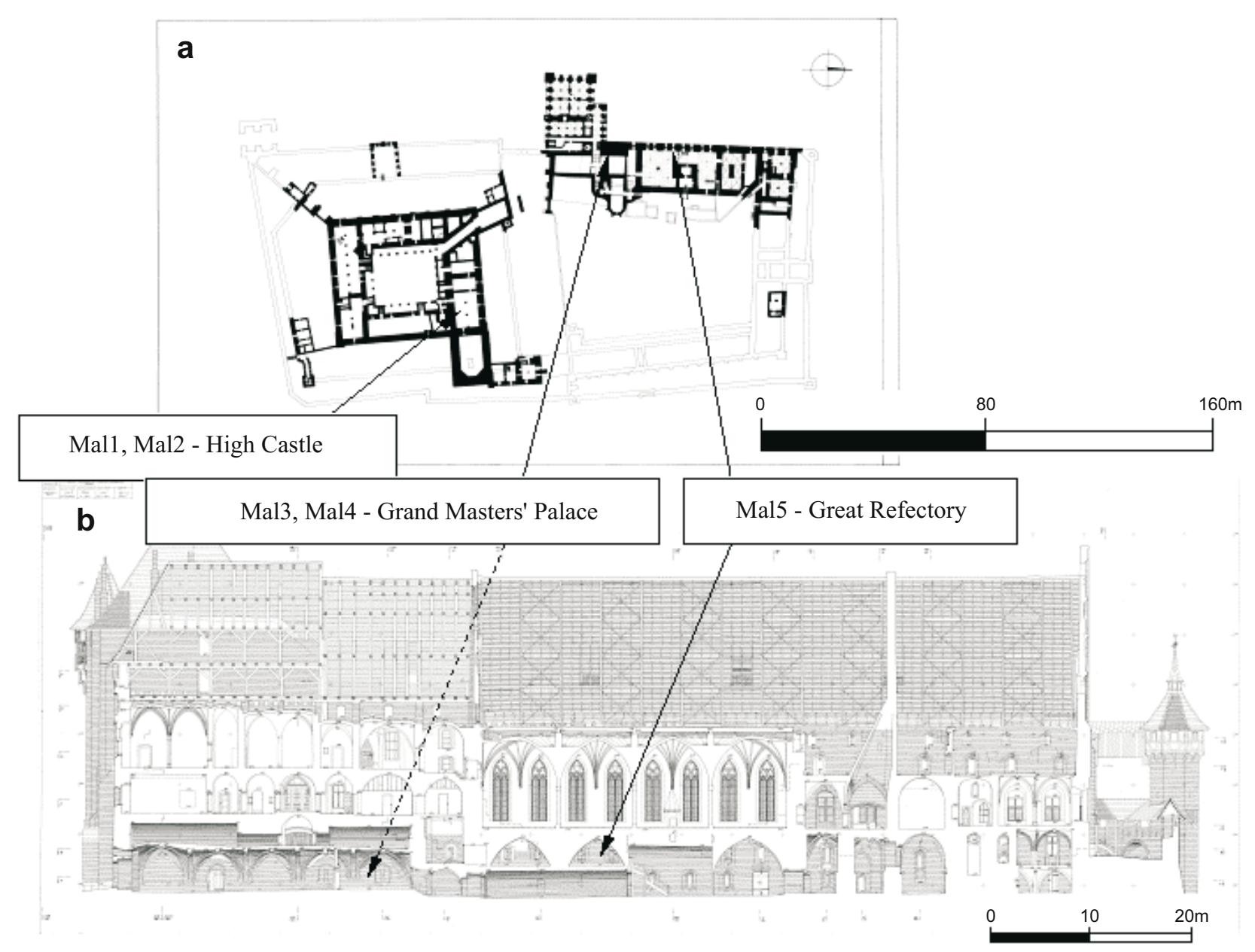

Fig. 1. Places of sample collection in Malbork Castle cellars. (a) Plan of the Castle. (b) The west wing of Middle Castle.

ity changes during heating. The measure of the TL signal after the i-th dose is a ratio of the light sum calculated for the glow curve obtained after the i-th dose to the light sum calculated for the glow curve obtained after the test dose. Both light sums are calculated for the same temperature range, which was chosen individually for each sample by means of a plateau test. The ratio of natural TL to laboratory excited (35 s of irradiation) regenerated $\mathrm{TL}$ signal (NTL/RTL) versus temperature was plotted for each of 24 aliquots, which were used for AD determination for a single brick sample. Then the temperature region was chosen, where the NTL/RTL ratio was constant simultaneously for all aliquots. The plateau temperature ranges used for dating were different for individual samples: $260-330^{\circ} \mathrm{C}-\mathrm{Mal1}, 360-400^{\circ} \mathrm{C}-\mathrm{Mal} 2,420-450^{\circ} \mathrm{C}$ - Mal3, $390-450^{\circ} \mathrm{C}-\mathrm{Mal} 4$ and $410-440^{\circ} \mathrm{C}$ in the case of Mal5. The subsequent regenerative $\beta$ doses (in seconds of irradiation with the $\beta$ source) were applied in all presented cases: 0 (natural TL measurement), $35 \mathrm{~s}, 45 \mathrm{~s}$, $55 \mathrm{~s}, 35 \mathrm{~s}$. The repetition of the initial dose at the end of the protocol served as a test of quality of the sensitivity change correction and signal reproducibility. For all measured samples the difference between results of the first and last measurement cycle (for this controlling dose of $35 \mathrm{~s}$ ) do not exceed 6 percent. Such result is commonly accepted in the OSL SAR technique (Wintle and Murray,
2006). It has to be stressed that the growth curve points lay always properly on a line, the TL signal from different aliquots was very homogeneous and in result a good precision of about $2 \%$ was achieved for the equivalent dose (ED). Fig. 2 presents, for illustrative purpose, an example of glow curves and plateau test curve for an aliquot of sample Mal2 together with the AD values obtained for all aliquots measured for this sample. The annual dose (AD) is calculated using the $\gamma$ spectrometry results (Oczkowski and Przegiętka, 1998). The depth of the sample in the wall is taken into account for the AD estimation as well as the averaged brick density. The moisture content which should be taken into account for the final calculations, is still under investigation. Currently the annual changes of wetness conditions in the cellars of the castle are tested.

\section{RESULTS AND DISCUSSION}

The preliminary results are presented in Table 1 . The dates given in this table were calculated for two extreme values of moisture content $-3 \%$ and $12 \%$. They limit a wide range of moisture content values, which are normally obtained in result of brick wall investigation (information given by restorers). Any statistical or systematic errors were not taken into account in these calcula- 
Table 1. Results of research carried out up to now for 5 brick samples collected in Malbork Castle. The presented dose values are not corrected for sample depth in wall, the moisture content and grain size $\left(D_{\beta}\right)$, but all these factors were taken into account in the preliminar age calculations. The presented calendar age ranges are calculated for the possible range of moisture content in bricks suggested by restorers (see text).

\begin{tabular}{|c|c|c|c|c|c|c|c|}
\hline Sample & $\begin{array}{l}\text { ED } \\
\text { (Gy) }\end{array}$ & $\begin{array}{c}\text { DK-40* } \\
(\mu \text { Gy/a) }\end{array}$ & $\begin{array}{l}D_{\text {Th-232* }}{ }^{*} \\
(\mu G y / a)\end{array}$ & $\begin{array}{l}\text { Du-238* } \\
(\mu \text { Gy/a) }\end{array}$ & $\begin{array}{c}D_{\beta}{ }^{*} \\
(\mu \text { gy/a })\end{array}$ & $\begin{array}{c}\text { Cosmic radiation } \\
(\mu \mathrm{G} / \mathrm{a})\end{array}$ & $\begin{array}{l}\text { Age ranges } \\
\text { (AD) }\end{array}$ \\
\hline Mal1 & $1.96 \pm 0.04$ & $508 \pm 5$ & $367 \pm 2$ & $192 \pm 2$ & $1947 \pm 13$ & 0 & $1158-1239$ \\
\hline Mal2 & $1.86 \pm 0.03$ & $499 \pm 24$ & $405 \pm 3$ & $287 \pm 3$ & $2062 \pm 69$ & 0 & $1205-1282$ \\
\hline Mal3 & $1.87 \pm 0.03$ & $548 \pm 5$ & $395 \pm 2$ & $344 \pm 4$ & $2270 \pm 15$ & 0 & $1269-1339$ \\
\hline Mal4 & $1.91 \pm 0.03$ & $575 \pm 5$ & $453 \pm 2$ & $348 \pm 2$ & $2388 \pm 14$ & 0 & $1309-1376$ \\
\hline Mal5 & $2.24 \pm 0.04$ & $538 \pm 4$ & $423 \pm 2$ & $355 \pm 2$ & $2272 \pm 12$ & $67 \pm 13$ & $1260-1331$ \\
\hline
\end{tabular}

tions. So the presented dates should be treated only as an illustration of the moisture content influence on the obtained result. The detailed investigations of wetness conditions and its seasonal changes are just being conducted by restorers. As it can be seen, the knowledge about the moisture conditions is crucial for the accuracy of obtained age, which could satisfy the historians of art. The very good precision of ED $(<2 \%)$ and brick radioactivity $(<1 \%)$ estimation do not lead to satisfactorily precise dates, if one has not made an effort to find a possibly well determined moisture content.

It was assumed that no cosmic rays reach the wall inside the cellar. The cosmic ray dose was estimated only for sample Mal5, because it was taken from the external wall of the fortress. The approximate formula was applied using the data given by Prescott (Prescott and Stephan, 1982; Aitken, 1985):
Table 2. Infinite matrix $y$ doses originated from 3 essential $y$ ray sources: ${ }^{40} \mathrm{~K},{ }^{232} \mathrm{Th}$ and ${ }^{238} \mathrm{U}$, for brick and mortar samples.

\begin{tabular}{|c|c|c|c|c|c|c|}
\hline \multirow{2}{*}{ Sample } & \multicolumn{2}{|c|}{$D_{K-40}(\mu G y / a)$} & \multicolumn{2}{|c|}{$\mathrm{D}_{\text {Th-232 }}(\mu \mathrm{Gy} / \mathrm{a})$} & \multicolumn{2}{|c|}{ Du-238 ( $\mu$ Gy/a) } \\
\hline & brick & mortar & brick & mortar & brick & mortar \\
\hline Mal1 & $508 \pm 5$ & \multirow{2}{*}{$173 \pm 2$} & $367 \pm 2$ & \multirow{2}{*}{$86 \pm 1$} & $192 \pm 2$ & \multirow{2}{*}{$77 \pm 1$} \\
\hline Mal2 & $499 \pm 24$ & & $405 \pm 3$ & & $287 \pm 3$ & \\
\hline Mal3 & $548 \pm 5$ & $138 \pm 1$ & $395 \pm 2$ & $64 \pm 1$ & $344 \pm 4$ & $53 \pm 1$ \\
\hline Mal4 & $575 \pm 5$ & $183 \pm 2$ & $453 \pm 2$ & $103 \pm 1$ & $348 \pm 2$ & $77 \pm 1$ \\
\hline
\end{tabular}

Fig. 3), in the belief that this volume is large enough to cover the range of all the photons in question and can be treated as a half of an infinite radioactive matrix. It was assumed that the brick activity is the same for all bricks as well as the mortar activity is homogeneous in the whole matrix. The brick-mortar matrix reflected the structure of wall built of vertical layers of stretcher bond,

$D_{C R}=\frac{1}{3}\left[176.792 e^{-\frac{h}{6.07}}-1.326\right]+\frac{1}{3}\left[176.792 e^{-\frac{(d-x)}{6.07}}-1.326\right]$

where $h=4.0(5) \mathrm{m}$ is the wall height over the place of sample collection, $d=2.8(1) \mathrm{m}$ is the wall thickness and $x=0.050(5) \mathrm{m}$ the inner sample depth in the wall. Other samples originate from the inner walls. The averaged thickness of walls and vaults in the castle is 3 and $6 \mathrm{~m}$, respectively. The analysis of the castle plans allows to assume that cosmic rays have an insignificant impact on the annual dose value in the case of all other samples.

All walls are constructed completely of bricks, but a source of inhomogeneity can be the mortar. A thick layer of mortar between bricks called our attention during the sample collection. The averaged brick size is $30 \times 14.5 \times 9 \mathrm{~cm}$ and the mortar layer thickness ranges from 2 to $3 \mathrm{~cm}$. This prompted us to check the difference between the brick and mortar radioactivity, so a sample of mortar was taken from each investigated wall for $\gamma$ spectrometry measurements. It turned out that the differences in radioactivity between both materials are quite large. Table 2 contains the comparison of mortar and brick infinite matrix $\gamma$ doses.

If age precision of about 20 years is aimed at in dating, such significant difference in brick and mortar activity requires a consideration how significant it is in the calculation of the annual dose. For this purpose, a computer model - a matrix of the activity value distribution in the wall of the size of $1 \times 1 \times 1 \mathrm{~m}$ was created (area B in which are horizontally translated one to the next along the wall surface by $15 \mathrm{~cm}$ (Fig. 4). The brick dimensions were $30 \times 15 \times 10 \mathrm{~cm}$ and the mortar layers under and be-

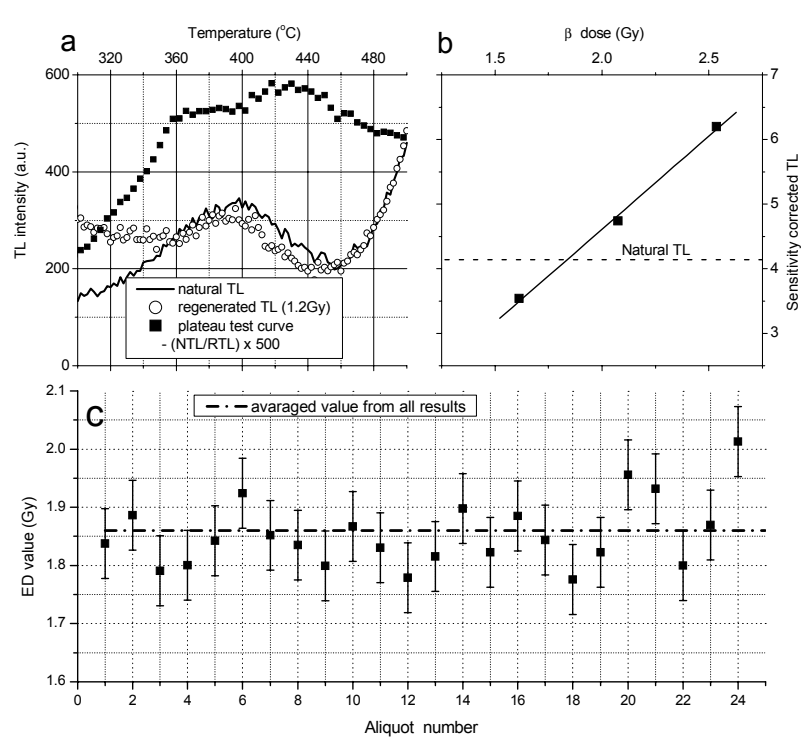

Fig. 2. Example glow curves, plateau test curve (a) and growth curve (b) for aliquot no. 1 of Mal2 sample. (c) Comparison of $A D$ values obtained for all 24 aliquots of sample Mal2. 


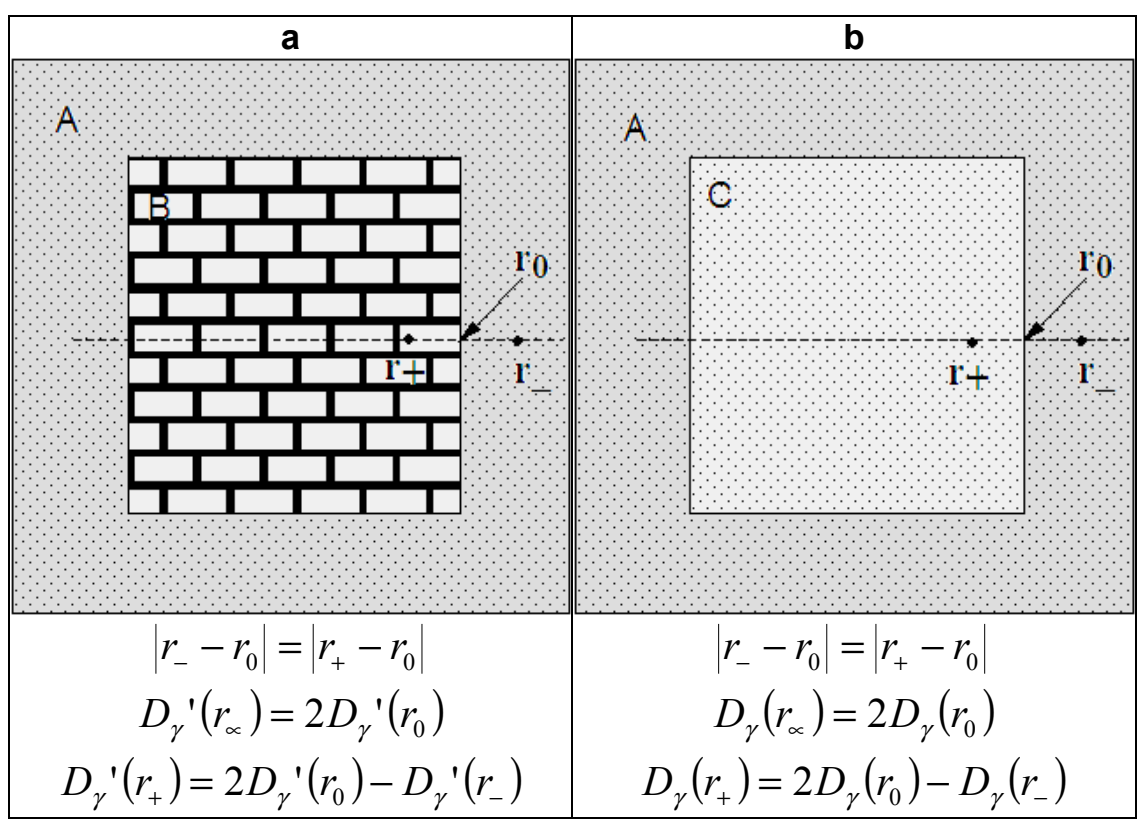

Fig. 3. Wall model used for the calculation of correction factors, which take into account the fact that mortar is less radioactive than bricks. The matrix of radioactive brick. (Symbols used in the figure are explained in the text.)

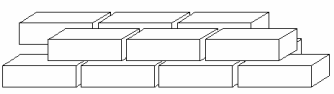

Fig. 4. Bond of the wall used for construction of the computer model of radioactive brick-mortar matrix.

tween the bricks were always of $2 \mathrm{~cm}$. The difference in annual $\gamma$ dose between the homogeneous (pure bricks area $\mathrm{C}$ in Fig. 3b) and inhomogeneous (brick-mortar area B in Fig. 3a) matrix was calculated for isotopes emitting the most energetic $\gamma$ rays. It turned out that only the $\gamma$ rays of energy higher than $100 \mathrm{keV}$ can have a significant impact on the investigated effect. The integration procedure called triplequad offered by MATLAB was used for the dose determination. The integrated function was in the following form:

$$
\frac{a_{\gamma}(r)}{\left(r-r_{-}\right)^{2}} \exp \left[-\mu_{\gamma} \cdot\left(r-r_{-}\right)\right]
$$

where $a_{\gamma}(r)$ is activity of the isotope emitting $\gamma$ photons of a certain energy in the point of coordinate $r, r_{\text {- }}$ is coordinate of the point in which the dose rate $\left(D_{\gamma}\left(r_{-}\right)\right)$is determined, $\mu_{\gamma}$ is the mass attenuation coefficient for $\gamma$ photons of defined energy. The last parameter was kept constant for the whole space. The values for given energies were found in NIST tables for ordinary concrete and corrected adequately to density of bricks. The function (4.2) has a singularity when $r=r$. and because of this $r$. had to be taken outside the radioactive wall matrix, which is the integration region. It was assumed that an infinite, inert and homogenous brick matrix extends around the radioactive matrix (area A in Fig. 3). The point $r$ - was always in front of the radioactive matrix. It lied on a line, which was perpendicular to the wall surface and crossed its geometric centre. The principle of superposition (Aitken, 1985) was used in order to obtain the dose rate values for points lying inside the active matrix $\left(D_{\gamma}\left(r_{+}\right)\right.$- pure bricks or $D_{\gamma}$ ' $\left(r_{+}\right)$- brick-mortar), what is actually needed for annual dose calculation. The value of dose rate for the infinite radioactive matrix $\left(D_{\gamma}{ }^{\prime}(\propto)\right.$ or $\left.D_{\gamma}(\propto)\right)$, necessary for these calculations, was taken as the limit of outside dose rate value, adequately $D_{\gamma}{ }^{\prime}\left(r_{-}\right)$and $D_{\gamma}\left(r_{-}\right)$, calculated for $r_{-}$approaching the active matrix surface $\left(r_{-} \rightarrow r_{0}\right)$. Then the dose rate for the brick-mortar and pure brick matrix are adequately:

$$
D_{\gamma}{ }^{\prime}\left(r_{+}\right)=D_{\gamma}{ }^{\prime}(\propto)-D_{\gamma}{ }^{\prime}\left(r_{-}\right)=2 D_{\gamma}{ }^{\prime}\left(r_{0}\right)-D_{\gamma}{ }^{\prime}\left(r_{-}\right)
$$

and

$$
D_{\gamma}\left(r_{+}\right)=D_{\gamma}(\propto)-D_{\gamma}\left(r_{-}\right)=2 D_{\gamma}\left(r_{0}\right)-D_{\gamma}\left(r_{-}\right)
$$

The ratio $D_{\gamma}{ }^{\circ}\left(r_{+}\right) / D_{\gamma}\left(r_{+}\right)$was calculated for different sample depths in the wall, for each isotope active in bricks, which emits $\gamma$ photons of energy higher than $100 \mathrm{keV}$, and for wide range of mortar activity $\left(A_{m}\right)$ to brick activity $\left(A_{b}\right)$ ratio. Fig. 5 shows some examples of the decrease of partial (originated from an individual isotope) annual $\gamma$ dose $\left(\left[D_{\gamma}\left(r_{+}\right)-D_{\gamma}{ }^{\prime}\left(r_{+}\right)\right] / D_{\gamma}\left(r_{+}\right)\right)$because of the lower mortar activity for four isotopes as a function of $A_{m} / A_{b}$ ratio for the depth of sample in the wall equal $5 \mathrm{~cm}$. In the case of a given sample the adequate depth value and $A_{m} / A_{b}$ ratios, which were obtained by spectrometry for the significant $\gamma$-emitting isotopes, were used for calculation of the annual dose corrections. Table 3 contains results of this procedure applied for the investigated samples.

Table 4 presents the differences between total $\gamma$ doses obtained for the both matrixes. The final impact of these differences on the age of samples (the difference between the ages calculated without taking into account presence of the mortar and the ages calculated for the mortar effect) is also shown. The value of seven years for the samples which are around 700 years old is not a large change $(\sim 1 \%)$, but this is a factor which, although is comparable to the ED precision $(<2 \%)$, always gives rise to the older 


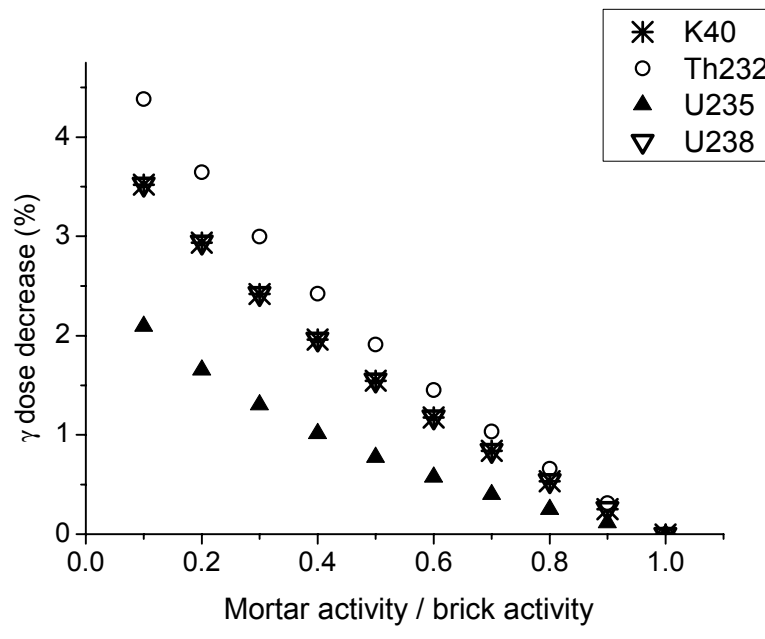

Fig. 5. Decrease of the annual $\gamma$ dose originated from the isotopes of the highest energy in each of radioactive series caused by wall inhomogeneity. The decrease dependence on the ratio of mortar activity to brick activity is demonstrated.

age, so taking it into account seems to be reasonable. Summing up, the inhomogeneity of the wall structure should be considered in the cases, when the ratio of the mortar activity to brick activity is lower than 0.5 and especially for the samples, which contain a lot of potassium.

The preliminary results are presented in Table 1. All the values agree with the dates mentioned by historians. These results prove that the TL method can reconstruct the history of a building. The detailed measurements of moisture content, which are just being conducted by the restorers, give hope for better precision, which could possibly satisfy the historians of art. The TL dosimeters were inserted into the wall in order to determine the $\gamma$ dose on site. The comparison of both annual dose determination techniques is intended.

\section{SUMMARY}

The investigated brick samples turn out to be a very good material for TL dating application. The equivalent dose determination precision $(<2 \%)$ is very high because of good quartz sample homogeneity and TL sensitivity. At the present stage of investigations, the most significant factor influencing the age precision is the uncertainty of the moisture content, which can produce the final age uncertainty of the order of $5 \%$. The presence of mortar and its relatively low activity can influence the age rather in minor range (uncertainty of $\sim 1 \%$ ), but for higher precision suspected by historians it should be considered. The presented method of determining the influence of lower mortar activity on the annual dose gives an approximation of the possible effects. The more sophisticated approach could take into account the real wall structure (much more complicated wall bond than the one used here) and more accurate mass attenuation coefficient value. However, it can be suspected that the improvement in correction factors would not compensate the significant effort, which had to be made in order to expand the model. On the other side, the smaller size of brick can
Table 3. Results of annual $\gamma$ dose correction factor calculations for individual radioactive series. In Thorium series ${ }^{228} \mathrm{Ac},{ }^{212} \mathrm{~Pb},{ }^{212} \mathrm{Bi}$ and ${ }^{208} \mathrm{TI}$ have significance. For Uranium - 238 series ${ }^{241} \mathrm{~Pb}$ and ${ }^{214} \mathrm{Bi}$. The relatively low ${ }^{235} \mathrm{U}$ content and simultaneously low energies of $\gamma$ rays emitted by isotopes of this series allow ignore this series in the calculations. The ratios of the mortar activity $\left(A_{m}\right)$ to brick activity $\left(A_{b}\right)$ for the individual radioactive series are also presented.

\begin{tabular}{l|cc|cc|cc}
\hline \multirow{2}{*}{ Sample } & \multicolumn{2}{|c|}{${ }^{232} \mathbf{T h}$} & \multicolumn{2}{c|}{${ }^{238} \mathbf{U}$} & \multicolumn{2}{c}{${ }^{40} \mathbf{K}$} \\
\cline { 2 - 7 } & $\mathbf{A}_{\mathbf{m}} / \mathbf{A}_{\mathbf{b}}$ & $\mathbf{f}_{\gamma}$ & $\mathbf{A}_{\mathbf{m}} / \mathbf{A}_{\mathbf{b}}$ & $\mathbf{f}_{\gamma}$ & $\mathbf{A}_{\mathbf{m}} / \mathbf{A}_{\mathbf{b}}$ & $\mathbf{f}_{\gamma}$ \\
\hline Mal1 & 0.234 & 0.963 & 0.407 & 0.982 & 0.340 & 0.978 \\
Mal2 & 0.212 & 0.962 & 0.273 & 0.976 & 0.346 & 0.978 \\
Mal3 & 0.162 & 0.959 & 0.155 & 0.970 & 0.251 & 0.973 \\
Mal4 & 0.229 & 0.952 & 0.226 & 0.973 & 0.319 & 0.976 \\
\hline
\end{tabular}

$\mathrm{f}_{\gamma}-\gamma$ dose correction factor

Table 4. Total annual $y$ dose obtained for the pure brick matrix and the matrix of bricks and mortar. The differences between ages calculated for both uncorrected and mortar corrected annual $y$ doses are shown in order to present the impact of the lower mortar activity on the age. The data calculated for the maximal moisture content $12 \%$ (for lower moisture content the values are smaller) and for the actual sample depth in the wall was taken as an example.

\begin{tabular}{lccc}
\hline Sample & $\begin{array}{c}\mathbf{D}_{\gamma} \\
(\mu \mathrm{G} / \mathrm{a})\end{array}$ & $\begin{array}{c}\mathbf{D}_{\gamma} \text { (corr) } \\
(\mu \mathrm{\mu G} / \mathrm{a})\end{array}$ & $\begin{array}{c}\text { Age }- \text { Age (corr) } \\
(\mathrm{a})\end{array}$ \\
\hline Mal1 & 720 & 701 & -7.1 \\
Mal2 & 805 & 782 & -6.9 \\
Mal3 & 870 & 842 & -7.2 \\
Mal4 & 930 & 900 & -6.9 \\
\hline
\end{tabular}

cause more considerable effects and in this case the model improvement can be worthy of consideration.

\section{REFERENCES}

Abrahamsen N, Jacobsen U, Mejdahl U and Mejdahl V, 1996. Brick kiln from SW Jutland: The kiln, historical outline of brick production and farm building in Jutland, magnetic and luminescence dating of the kiln. Proceedings 7. Nordic Conf. on the Application of Scientific Methods in Archaeology, Savonlinna, Finland: 61-73.

Aitken MJ, 1985. Thermoluminescence Dating. London, Academic Press: $359 \mathrm{pp}$.

Antrobus A, 2004. Luminescence dating of brick chimneys. Vernacular architecture 35: 21-31.

Bailiff IK and Holland N, 2000. Dating bricks of the last two millennia from Newcastle upon Tyne: a preliminary study. Radiation Measurements 32(5-6): 615-619, DOI 10.1016/S1350-4487(99)002863.

Bailiff IK and Mikhailik VB, 2004. The use of calcium silicate bricks for retrospective dosimetry. Radiation Measurements 38(1): 91-99, DOI 10.1016/j.radmeas.2003.07.004.

Bailiff IK and Petrov SA, 1999. The Use of the 210C TL Peak in Quartz for Retrospective Dosimetry. Radiation Protection Dosimetry 84(1): 551-554.

Banerjee D, Bøtter-Jensen L and Murray AS, 1999. Retrospective dosimetry: Preliminary use of the single aliquot regeneration (SAR) protocol for the measurement of quartz dose in young house bricks. Radiation Protection Dosimetry 84(1): 421-426.

Better-Jensen H and Murray AS, 1999. Developments in optically stimulated luminescence techniques for dating and retrospective dosimetry. Radiation Protection Dosimetry 84(1): 307-316.

Goedicke C, Slusallek K and Kubelik M, 1981. Thermoluminescence Dating in Architectural History: Venetian Villas. The Journal of the Society of Architectural Historians 40(3): 203-217, DOI 10.2307/989694.

Goedicke C, Slusallek K and Kubelik M, 1986. Thermoluminescence Dating in Architectural History: The Chronology of Palladio's 
Villa Rotonda. The Journal of the Society of Architectural Historians 45(4): 396-407, DOI 10.2307/990210.

Göksu HY and Schwenk P, 2000. Thermoluminescence dating of terrazzo from the monastery church of Tegernsee (Bavaria, Germany) using the $210^{\circ} \mathrm{C}$ TL peak of quartz. Radiation and Environmental Biophysics 39(4): 301-308, DOI $10.1007 / \mathrm{s} 004110000063$

Jesionowski B, 2006. Kościół Najświętszej Panny Marii na Zamku w Malborku - nowe odkrycia i interpretacje jego dziejów (Church of Our Lady in Malbork Castle - new discoveries and interpretations of history). Malbork, Studia Zamkowe 2: 67-95 (in Polish).

Murray AS and Roberts RG, 1998. Measurements of the equivalent. dose in quartz using a regenerative-dose single-aliquot protocol. Radiation Measurements 29(5): 503-515, DOI 10.1016/S13504487(98)00044-4.

Oczkowski HL and Przegiętka KR, 1998. Partial Matrix Doses for Thermoluminescence Dating. Physica Scripta 58(5): 534-537, DOI 10.1088/0031-8949/58/5/019.

Powierski J, 1979. Chronologia początków Malborka (Chronology of the beginning of Malbork Castle). Zapiski Historyczne XLIV(2): 5-32 (in Polish).

Prescott JR and Stephan LG, 1982. Contribution of cosmic radiation to environmental dose. PACT 6: 17-25.

Sanderson DCW and Bingham RG, 2004. Luminescence dating of bricks from Angkor Borei, southern Cambodia. Scottish Universities Environmental Research Centre Research Report: 26pp.

Torbus T, 1998. Die Konventsburgen im Deutschordensland Preußen (The convent castles in Teuthonic Order State). München, Schriften des Bundesinstituts für ostdeutsche Kultur und Geschichte 11: 956pp (in German).

Trupinda J, 2006: Skrzydło północne Zamku Wysokiego - dzieje, kształt architektoniczny i wyposażenie w świetle źródeł pisanych (The north wing of High Castle - history, architecture and fittings in the light of sources). Malbork, Zamek Wysoki w Malborku. Interdyscyplinarne badania skrzydła pótnocnego: 13-45 (in Polish).

Wintle AG and Murray AS, 2006. A review of quartz optically stimulated luminescence characteristics and their relevance in singlealiquot regeneration dating protocols, Radiation Measurements 41(4): 369-391, DOI 10.1016/j.radmeas.2005.11.001. 